\title{
Effect of Nanocomposite Structures on Fracture Behavior of Epoxy-Clay Nanocomposites Prepared by Different Dispersion Methods
}

\author{
Mohammad Bashar, ${ }^{1}$ Pierre Mertiny, ${ }^{1}$ and Uttandaraman Sundararaj ${ }^{2}$ \\ ${ }^{1}$ University of Alberta, 4-9 Mechanical Engineering Building, Edmonton, AB, Canada T6G 2G8 \\ ${ }^{2}$ University of Calgary, 2500 University Drive NW, Calgary, AB, Canada T2N 1N4 \\ Correspondence should be addressed to Mohammad Bashar; bashar@ualberta.ca
}

Received 13 February 2014; Accepted 13 May 2014; Published 2 June 2014

Academic Editor: Yanbao Zhao

Copyright ( $) 2014$ Mohammad Bashar et al. This is an open access article distributed under the Creative Commons Attribution License, which permits unrestricted use, distribution, and reproduction in any medium, provided the original work is properly cited.

\begin{abstract}
The effects of organic modifier and processing method on morphology and mechanical properties of epoxy-clay nanocomposites were investigated. In this study, the preparation of nanocomposites by exfoliation-adsorption method involved an ultrasonic mixing procedure, and mechanical blending was used for in situ intercalative polymerization. The microstructure study revealed that the organoclay, which was ultrasonically mixed with the epoxy, partially exfoliated and intercalated. In contrast, organoclay remained in phase-separated and flocculated state after the mechanical blending process. Tensile stiffness increased significantly for the nanocomposite prepared by ultrasonic dispersion method through realizing the reinforcing potential of exfoliated silicate layers. Nanocomposites with exfoliated and intercalated nanoclay morphology were ineffective in enhancing the fracture toughness whereas nanocomposites with phase-separated and flocculated morphology have improved crack resistance predominantly by crack deflecting and pinning mechanisms.
\end{abstract}

\section{Introduction}

Polymer nanocomposites are multifunctional materials, having unique properties that distinguish them from traditional polymer microcomposites. Recently it has been demonstrated that nanoscale dispersion of layered silicate in relatively small quantities can significantly enhance the properties of a substrate polymer [1,2]. The inorganic particle layered silicate commonly known as nanoclay or organoclay has a lamellar structure consisting of hydrous magnesium or aluminum silicates [3]. Having high aspect ratio, large surface area, and good interfacial properties, layered silicate clay added to a polymer matrix can contribute to significant cost savings as a property enhancer. Clay-containing polymer nanocomposites may offer beneficial properties, such as good mechanical properties [1, 2, 4-9], dimensional stability, barrier properties [4], flame retardancy [4, 10], optical properties, and thermal stability $[1,4]$. Polymer clay composites exhibit three distinct morphologies, that is, conventional segregated clay phase and intercalated and exfoliated structures $[3,11]$. Improved mechanical, thermal, and barrier properties are usually obtained for an exfoliated architecture; that is, individual silicate lamellae are homogenously distributed in the polymer matrix. The degree of clay exfoliation and intercalation depends on the type of clay $[8,12]$, cation exchange capacity $[13,14]$, chemical nature of the interlayer cations $[7-10,12]$, curing agent $[6,15]$, curing temperature and time $[9,12,15,16]$, resin type $[16,17]$, and dispersion method $[18,19]$. There are several processing routes that can lead to well-dispersed layered silicate nanocomposite; these are in situ intercalative polymerization $[7,14]$, exfoliationadsorption [10,20], and melt processing [18].

Individual silicate layers provide excellent stiffness and strength in two dimensions due to their high aspect ratio, stiffness, and interaction at the molecular level. Lan and Pinnavaia [5] and Pinnavaia et al. [21] attributed the exceptional increase in the stiffness of nanocomposites in an exfoliated state to a reinforcing effect through stress transfer 
to the rigid individual silicate nanosheets. Likewise, Messersmith and Giannelis observed significant improvement in the dynamic storage modulus when dispersing organoclay into an epoxy matrix [6]. To date, various researchers have documented enhancement in epoxy mechanical properties; notably Kornmann et al. [7, 9], Zilg et al. [8], Xidas and Triantafyllidis [22], Becker et al. [17], Miyagawa and Drzal [20], Zerda and Lesser [23], Yasmin et al. [24], and Kinloch and Taylor [25] all recognized stiffness increase in the epoxyclay nanocomposites.

Furthermore, nanoclay has the ability to simultaneously increase toughness and stiffness of a polymer. In a study, Zilg et al. [8] observed that the extent of layered silicate exfoliation is directly related to nanocomposite stiffness, while fracture toughness is inversely affected by the exfoliation state. According to these researchers, the intercalated and/or phase-separated clay particles would be more effective in impeding crack propagation than the delaminated isolated clay platelets. Similarly, Kornmann et al. [7] showed that conventionally filled epoxy-clay composite resulted in the best toughening effect, and Miyagawa and Drzal [20] inferred that larger intercalated organoclay particles provided better fracture resistance than the exfoliated platelets. Moreover, Becker et al. [17] and Siddiqui et al. [26] demonstrated increase in polymer fracture toughness with a mixture of mostly intercalated and exfoliated organoclay in epoxy. Studies conducted so far on the fracture and deformation mechanisms of nanoclay-filled epoxy have qualitatively shown evidence of crack deflection, crack pinning, cavitation, and matrix deformation phenomena that improved crack propagation resistance in nanocomposites [19, 23, 27, 28]. Zerda and Lesser [23] documented crack deflection and branching by intercalated nanoclay diverting cracks in a tortuous path while creating additional fracture surface area. In epoxy-clay nanocomposites, formation of microcracks within the clay interlayers and subsequent propagation associated with the creation of new surface area due to crack deflection were considered to be the primary energy dissipation mechanisms by Wang et al. [27]. Liu et al. [28] identified several crack resistance phenomena, particle-matrix interfacial debonding, microvoiding, matrix shear yielding, and crack deflection to work cooperatively in an intercalated nanocomposite. Liu et al. [19] showed crack pinning and crack tip blunting (e.g., localized matrix deformation) mechanisms to function together or separately in different nanoclay-filled epoxy systems made by various preparation techniques.

The above literature review clearly demonstrates considerable disagreement and differences in opinion among researchers on the operative crack resistance mechanism in epoxy-clay nanocomposites and its dependence on the nanoclay morphology (i.e., exfoliated, intercalated, and phaseseparated). Therefore, it is important to understand the effect of nanoclay microstructure on the deformation behavior of the clay reinforced polymers. Material properties such as matrix cross-link density, particle morphology, and size also influence the toughness of the modified epoxy. Nanocomposite processing in fact affects the organoclay dispersion and its microstructure and consequently has pronounced influence on the fracture micromechanism. The need for a systematic evaluation from processing to microstructure evolution associated with final mechanical property development of the micro-/nanocomposites derived from organoclay would necessitate further study. Therefore, this paper highlighted synthesis, characterization, and micromechanism of fracture process in epoxy-clay nanocomposites. The present paper explored the effect of different nanoclay dispersion methods on the generated microstructure/nanostructure and, hence, the influence of these morphologies on the fracture behavior of the epoxy-clay nanocomposites. Different characterization and experimental techniques were involved to study the morphology and mechanical properties of resulting nanocomposites. A correlation between microstructure and fracture properties of the nanocomposites is ascertained in light of the crack resistance micromechanism.

\section{Materials and Methods}

2.1. Materials. For this study a bisphenol-A epoxy resin (EPON 826, epoxide equivalent weight 178-186 g/eq) and non-MDA polyamine curing agent (EPIKURE 9551) were obtained from Momentive (Columbus, OH, USA). Commercially available organoclays Nanomer I.30E $\left(\mathrm{CH}_{3}\left(\mathrm{CH}_{2}\right)_{17}\right.$ $\left.\mathrm{NH}_{3}-\mathrm{MMT}\right)$ and Nanomer I.28E $\left(\mathrm{CH}_{3}\left(\mathrm{CH}_{2}\right)_{17} \mathrm{~N}\left(\mathrm{CH}_{3}\right)_{3}\right.$ MMT) and PGW-an unmodified sodium montmorillonite clay (Na-MMT)-were supplied by Nanocor Inc. (Hoffman Estates, IL, USA). The organoclays I.30E and I.28E were, respectively, modified with primary and quaternary alkylammonium ions.

2.2. Preparation of the Epoxy-Clay Nanocomposites. Nanocomposites were synthesized by two separate nanoclay dispersion schemes. In situ intercalative polymerization was performed using a mechanical agitator; this is hereafter termed as mechanical dispersion. An exfoliation-adsorption process was carried out using an ultrasonic probe with the aid of the solvent acetone, which is hereafter designated as ultrasonic dispersion. Figure 1 shows process flow diagrams for the two methods.

2.2.1. Mechanical Dispersion. At first, the nanoclay I.30E was dried in an oven at $120^{\circ} \mathrm{C}$ for 24 hours and subsequently allowed to cool down to room temperature. Then, a measured amount of nanoclay was added to preheated EPON 826 resin at $60^{\circ} \mathrm{C}$ and mechanically mixed for 30 minutes with an impeller-type mechanical mixer running at 900 revolutions per minute. Then, a stoichiometric amount of the curing agent (i.e., $36 \mathrm{~g}$ of EPIKURE 9551 was used per $100 \mathrm{~g}$ of EPON 826) was added to the epoxy-clay solution, followed by mechanical mixing at $60^{\circ} \mathrm{C}$ for five minutes. Any entrapped air and volatiles formed during mixing with the curing agent were evacuated by a vacuum pump operated at $80 \mathrm{kPa}$ for 20 minutes. The final mixture was cured in an open mold made with mild steel having interior dimensions of $21 \mathrm{~cm}$ by $11.5 \mathrm{~cm}$ by $2.5 \mathrm{~cm}$. Curing of the epoxy and nanoclay blend occurred in an oven at $120^{\circ} \mathrm{C}$ for two hours. Composite samples having $1 \mathrm{wt} \%, 2 \mathrm{wt} \%$, and $3 \mathrm{wt} \%$ of I.30E clay were produced using this method. 


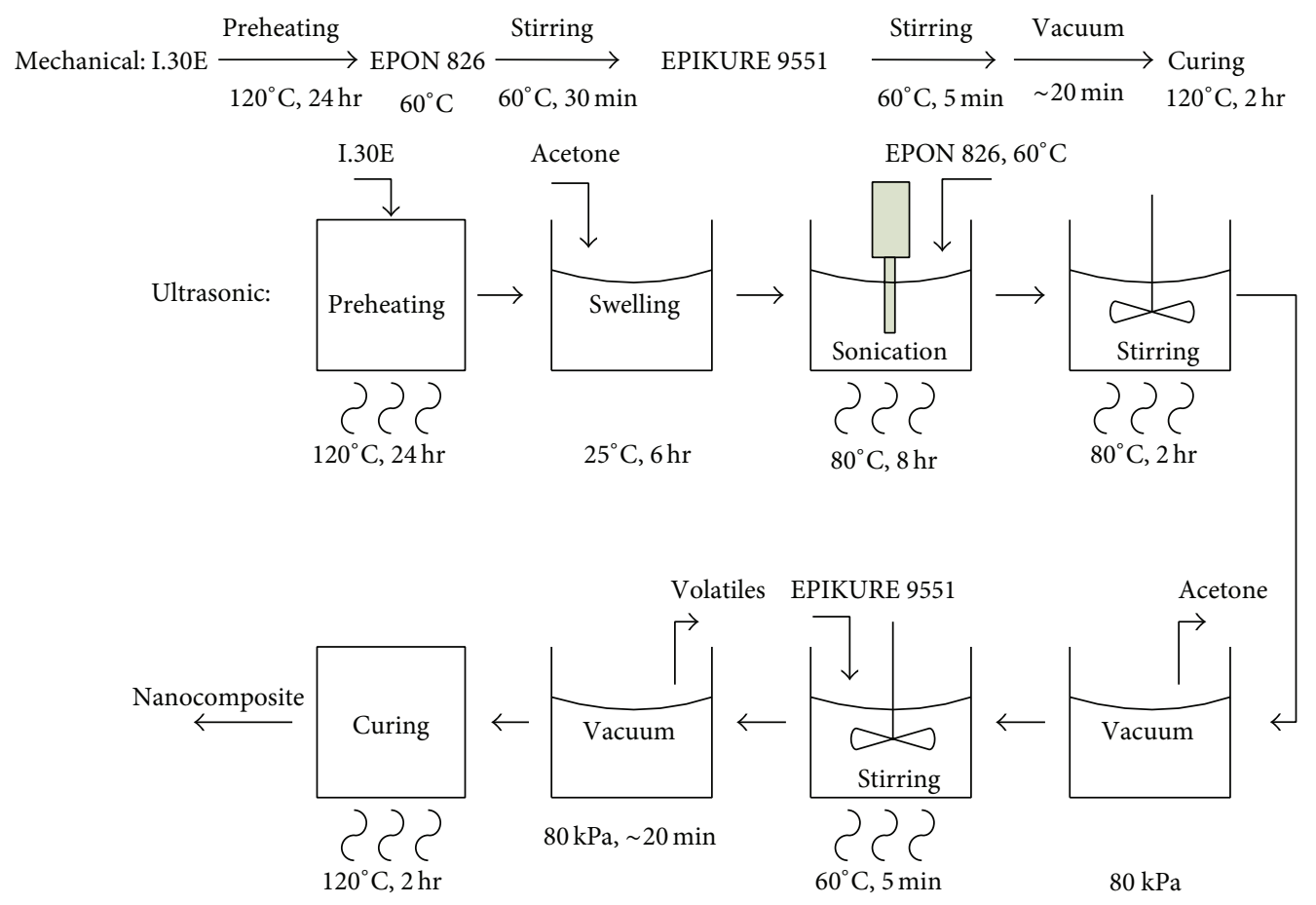

FIgURE 1: Process flow diagram of nanocomposite fabrication methods.

2.2.2. Ultrasonic Dispersion. At the beginning of the ultrasonic dispersion process, a specified amount of dried nanoclay was added to acetone. The mixture was then held at room temperature for six hours. During this time, diffusion of solvent into the clay interlayers and swelling of the interlayers occurred. In addition, the solvent acetone lowers the viscosity of the epoxy prepolymer, assisting the epoxy precursor to penetrate into the interlamellar region of the nanoclay $[10$, 20]. The solution was then mixed with the desired amount of EPON 826 resin preheated at $60^{\circ} \mathrm{C}$ and subsequently sonicated at $80^{\circ} \mathrm{C}$ for eight hours with a Branson model S75 Sonifier (Branson Ultrasonics Corporation, Danbury, CT, USA). The ultrasonic probe was operated at $75 \mathrm{~W}$ power output with $20 \mathrm{kHz}$ output frequency. A step horn sonotrode with a $12.7 \mathrm{~mm}$ tip diameter was used to transmit ultrasonic energy. Afterward, the solution was mechanically blended for two hours. Previously, it has been observed by Hutchinson et al. [29] that preconditioning of epoxy with organoclay resulted in increased exfoliation of the nanoclay. Acetone was removed from the solution by vacuum extraction performed at $80 \mathrm{kPa}$. Finally, the epoxy-clay blend was mixed with EPIKURE 9551 curing agent and cured in a manner similar to that described above for mechanical dispersion. Nanocomposites containing $1 \mathrm{wt} \%, 2 \mathrm{wt} \%$, and $3 \mathrm{wt} \%$ I.30E, $1 \mathrm{wt} \% \mathrm{I} .28 \mathrm{E}$, and $1 \mathrm{wt} \%$ PGW clay were produced according to this procedure.

2.3. X-Ray Diffraction. A Rigaku Geigerflex 2173 diffractometer (Rigaku Corporation, Tokyo, Japan) fitted with a Co tube and a graphite monochromator was used to obtain $\mathrm{X}$-ray diffraction (XRD) traces. XRD traces were analyzed to measure the basal spacing between the silicate layers. The diffractometer was operated at $40 \mathrm{kV}$ and $30 \mathrm{~mA}$. Wide-angle $\mathrm{X}$-ray diffraction (WAXD) traces of clay powders and cured nanocomposites were taken at angles ranging from $2 \theta=1$ to $30^{\circ}$ at a rate of $0.008^{\circ} \mathrm{sec}^{-1}$.

2.4. Microscopy. Transmission electron microscopy (TEM) offered direct visualization of the nanocomposite morphology. Ultrathin 40 60 nm sections were cut using a diamond knife in a Reichert-Jung Ultracut E microtome (C. Reichert Optische Werke AG, Vienna, Austria). Thin sections were then placed onto 300 mesh copper grids and examined by a Morgagni 268 transmission electron microscope (FEI, Hillsboro, OR, USA) with an acceleration voltage of $80 \mathrm{kV}$.

Fracture surfaces of neat epoxy and the corresponding nanocomposites were examined by a JEOL 6301F field emission scanning electron microscope (JEOL Ltd., Tokyo, Japan). Scanning electron microscopy (SEM) was performed on gold coated fracture surfaces of single edge notch bend (SENB) specimens at an acceleration voltage of $5 \mathrm{kV}$.

2.5. Tensile Testing. The tensile modulus, tensile strength, and tensile elongation at break were determined according to the standard ASTM D 638-03 using the MTS 810 machine. Dog-bone-shaped specimens with narrow section length of $57 \mathrm{~mm}$, width of $13 \mathrm{~mm}$, and thickness of $3.5 \mathrm{~mm}$ were tested under load control condition at a constant loading rate of $4.5 \mathrm{~N} \mathrm{sec}^{-1}$. 
2.6. Fracture Toughness Testing. The fracture toughness of the specimens was determined by conforming to the procedure outlined in the standard ASTM D 5045-99. The critical stress intensity factor, $K_{\mathrm{IC}}$, and strain energy release rate, $G_{\text {IC }}$, were determined according to linear elastic fracture mechanics principles. Equation (1) was used to calculate fracture toughness [30]. Specimens were loaded under planestrain condition in three-point bending until failure occurred from an initially prepared sharp precrack. Testing was conducted using a MTS 810 universal tester (MTS Systems Corporation, Eden Prairie, MN, USA) at a crosshead speed of $0.2 \mathrm{~mm} \mathrm{~min}^{-1}$ :

$$
\begin{gathered}
K_{I}=\left(\frac{P}{B W^{1 / 2}}\right) f(x) \quad \text { with } x=\frac{a}{W} \\
f(x)=6 x^{1 / 2} \frac{1.99-x(1-x)\left(2.15-3.93 x+2.7 x^{2}\right)}{(1+2 x)(1-x)^{3 / 2}},
\end{gathered}
$$

where $f$ is a geometric factor, $P$ is the failure load, $B$ is the specimen thickness, $W$ is the specimen width, and $a$ is the overall crack length.

\section{Results and Discussion}

3.1. Morphology of the Epoxy-Clay Nanocomposites. The microstructure of epoxy nanocomposites was studied by WAXD and TEM. Table 1 presents intergallery spacing of the organoclays and their respective nanocomposites composed of $1 \mathrm{wt} \%$ of the organoclay. In Table 1 , the $d$-spacing, $d_{001}$, of the nanocomposite prepared by ultrasonic mixing of $1 \mathrm{wt} \%$ I.30E clay with epoxy was estimated by TEM microscopy, as no reflection peak (see Figure 2) was noticed from WAXD traces. Absence of a reflection peak signifies either an exfoliated or an intercalated structure with interlayer distance exceeding $8.83 \mathrm{~nm}$ (which is the detection limit for WAXD, i.e., $2 \theta \geq 1^{\circ}$ ). The epoxy nanocomposite that was reinforced with the I.28E clay resulted in slightly expanded basal spacing of $d_{001}=2.85 \mathrm{~nm}$. The increase in layer separation from $2.39 \mathrm{~nm}$ to $2.85 \mathrm{~nm}$ most likely occurred due to epoxy solvation that took place during the ultrasonic blending phase. Pinnavaia et al. [21] reported a $d$-spacing of $d_{001}=3.69 \mathrm{~nm}$ when a similar quaternary alkylammonium ion, $\mathrm{CH}_{3}\left(\mathrm{CH}_{2}\right)_{17} \mathrm{~N}\left(\mathrm{CH}_{3}\right)_{3}{ }^{+}$, exchanged clay was swollen by the epoxy resin. The intergallery spacing of the inorganic PGW clay remained unaltered indicating that this composite has phase-separated clay structures. A phaseseparated morphology implies that the epoxy resin was not able to effectively penetrate between the clay platelets. This type of morphology is normally expected for untreated clays.

Figure 2 shows diffraction patterns of the cured epoxy nanocomposites containing various weight fractions of the I.30E clay fabricated by two different processing techniques. No distinguishable diffraction peak was observed for the nanocomposites produced by ultrasonic mixing containing $1 \mathrm{wt} \%$ and $2 \mathrm{wt} \%$ I.30E clay, but the composite having $3 \mathrm{wt} \%$ clay showed a distinct peak revealing an interlayer spacing of $d_{001}=2.73 \mathrm{~nm}$. In contrast, mechanical mixing generated a combination of intercalated and phase-separated architectures as evidenced by the broadening of the diffraction peak

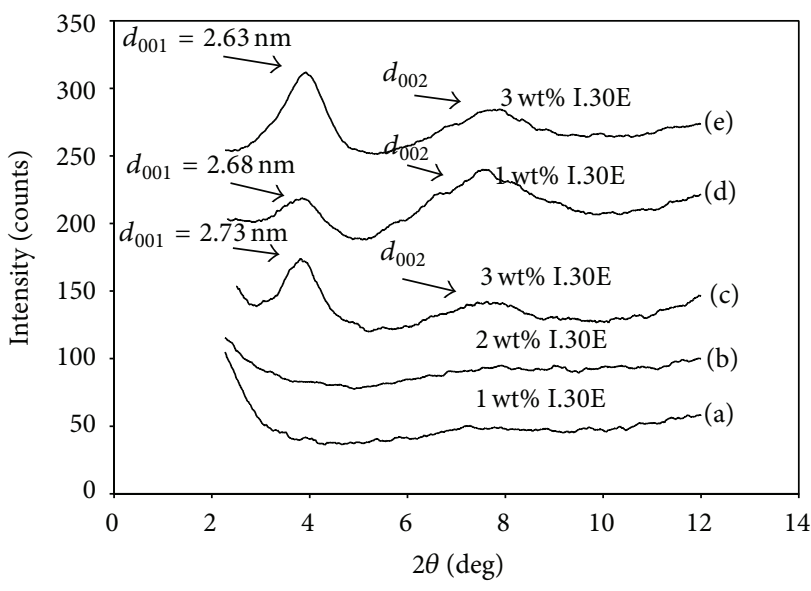

FIGURE 2: X-ray diffraction patterns of nanocomposites: (a), (b), and (c) prepared by ultrasonic dispersion and (d) and (e) by mechanical dispersion of I.30E clay.

with the scattering apex representing interlayer spacing of $d_{001}=2.68 \mathrm{~nm}$ and $2.63 \mathrm{~nm}$, respectively, for the $1 \mathrm{wt} \%$ and $3 \mathrm{wt} \% \mathrm{I} .30 \mathrm{E}$ clay loadings.

From the TEM images in Figure 3 it is apparent that the mixing techniques have greatly influenced the degree of the dispersion of I.30E nanoclay. The sample made by the ultrasonic technique displays partially exfoliated as well as laminated parallel platelets with a layer separation of 10-15 nm (see Figure 3(a)) whereas the nanocomposite prepared by mechanical mixing appears to retain its stacked layer structures as tactoids (intercalated and phase-separated clay agglomerates). Figure 4 shows the randomly distributed intercalated clay tactoids in the epoxy that was modified with the I.28E clay and larger clay microaggregates for the composite made with the unmodified PGW clay. The white areas shown in Figures 3(d) and 4(b) were formed during the ultramicrotoming process due to severing of the clay particles from the epoxy matrix. In agreement with the observation made by Zilg et al. [8] and Lan et al. [12], we also found that the primary ammonium ion is more effective than the quaternary ammonium ion in increasing the interlamellar distance of the layered silicate. According to Lan et al. [12] the apparent differences in the microstructure of the two organoclay systems can be explained by the catalytic influence of the alkylammonium ion on the epoxy-amine curing reaction: $\mathrm{CH}_{3}\left(\mathrm{CH}_{2}\right)_{17} \mathrm{NH}_{3}{ }^{+}>\mathrm{CH}_{3}\left(\mathrm{CH}_{2}\right)_{17} \mathrm{~N}\left(\mathrm{CH}_{3}\right) \mathrm{H}_{2}{ }^{+}>$ $\mathrm{CH}_{3}\left(\mathrm{CH}_{2}\right)_{17} \mathrm{~N}\left(\mathrm{CH}_{3}\right)_{2} \mathrm{H}^{+}>\mathrm{CH}_{3}\left(\mathrm{CH}_{2}\right)_{17} \mathrm{~N}\left(\mathrm{CH}_{3}\right)_{3}{ }^{+}$.

This catalytic effect is primarily due to the acidity of the organic cation in the presence of hydrogen of the ammonium group. It is deduced that in the I.30E clay-filled epoxy, intragallery catalytic polymerization rate was relatively higher than the extragallery polymerization, which caused further separation of the clay platelets. Previously, it was documented by Wang and Pinnavaia [31] and Kornmann et al. [9] that homopolymerization of the epoxy was facilitated in the presence of the acidic surface modifier of the organosilicate at a sufficiently higher temperature. However, in this study, it is assumed that the present curing conditions 
TABLE 1: Clay, organic modifier, $d$-spacing, and corresponding nanocomposite morphology.

\begin{tabular}{|c|c|c|c|}
\hline Clay & Organic modifier & $\begin{array}{l}d \text {-spacing of the } \\
\text { organoclay, } d_{001}{ }^{a}\end{array}$ & $\begin{array}{l}\text { Morphology and } d \text {-spacing of the } \\
\text { organoclay (1 wt\%) in cured epoxy }{ }^{\mathrm{a}, \mathrm{b}}\end{array}$ \\
\hline I. $30 \mathrm{E}$ & $\mathrm{CH}_{3}\left(\mathrm{CH}_{2}\right)_{17} \mathrm{NH}_{3}^{+}$ & $2.23 \mathrm{~nm}$ & $\begin{array}{c}10 \sim 15 \mathrm{~nm} \text {, exfoliated/intercalated (U) } \\
\text { (measured by TEM) } \\
2.68 \mathrm{~nm} \text {, phase-separated }(\mathrm{M})\end{array}$ \\
\hline I. $28 \mathrm{E}$ & $\mathrm{CH}_{3}\left(\mathrm{CH}_{2}\right)_{17} \mathrm{~N}\left(\mathrm{CH}_{3}\right)_{3}^{+}$ & $2.39 \mathrm{~nm}$ & $2.85 \mathrm{~nm}$, intercalated $(\mathrm{U})$ \\
\hline PGW & None & $1.24 \mathrm{~nm}$ & $1.24 \mathrm{~nm}$, phase-separated $(\mathrm{U})$ \\
\hline
\end{tabular}

${ }^{a}$ Interlayer spacing was measured using the prominent diffraction peak from XRD traces.

${ }^{\mathrm{b}} \mathrm{U}$ : ultrasonic mixing; M: mechanical mixing.

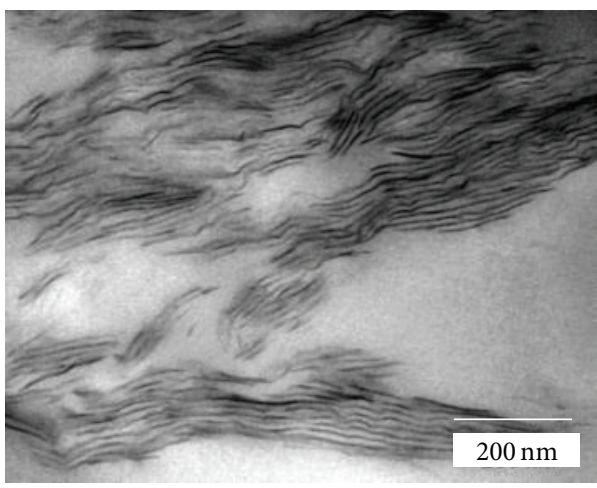

(a)

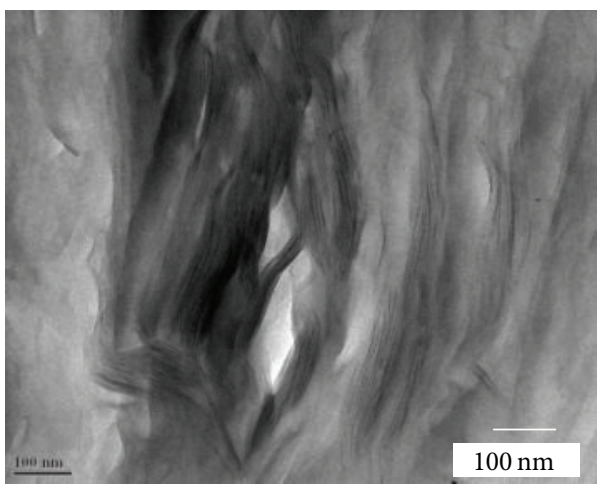

(c)

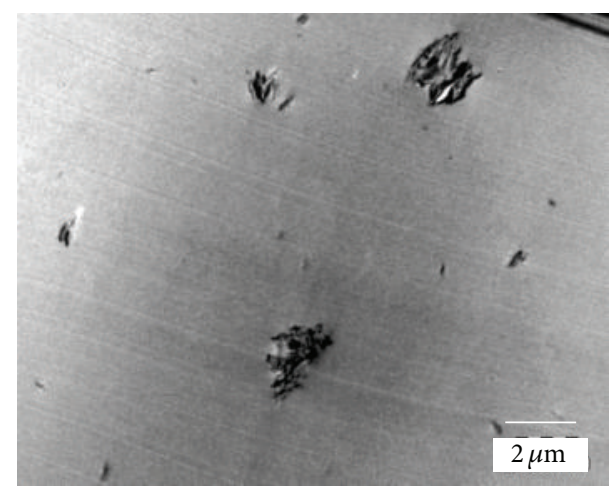

(b)

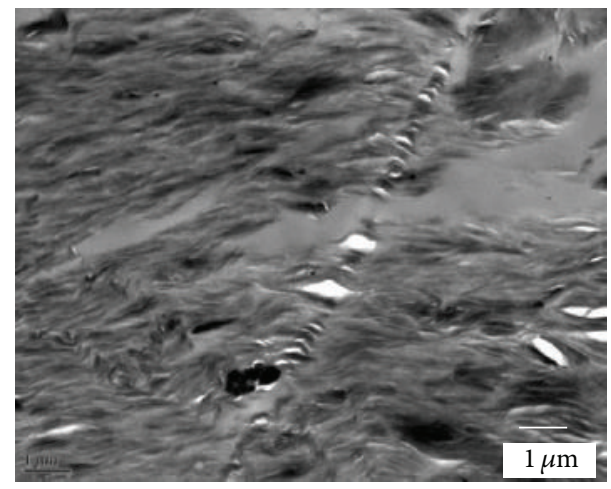

(d)

FIGURE 3: TEM micrographs of nanocomposites containing $1 \mathrm{wt} \%$ I.30E made by (a) and (b) ultrasonic dispersion and (c) and (d) mechanical mixing.

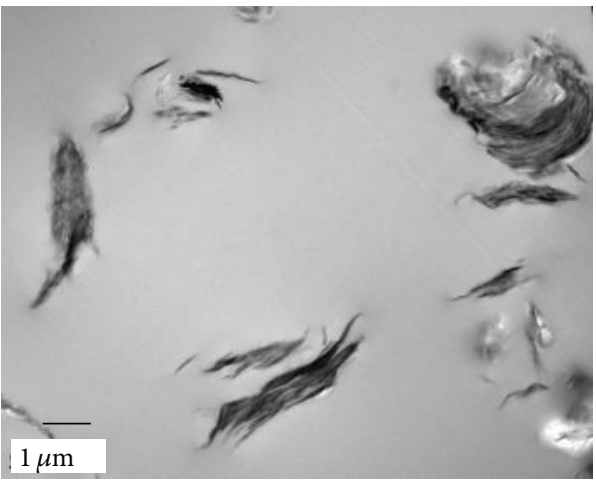

(a)

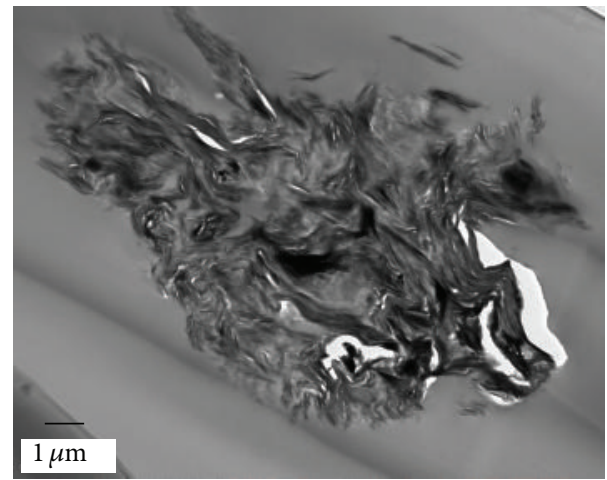

(b)

FIGURE 4: TEM images of nanocomposites comprised of (a) I.28E and (b) PGW clay in epoxy. 
TABle 2: Property of epoxy nanocomposites containing various concentrations of I.30E clay.

\begin{tabular}{|c|c|c|c|c|c|c|}
\hline $\begin{array}{l}\text { Filler matrix } \\
\text { loading }(\mathrm{wt} \%)^{\mathrm{a}}\end{array}$ & $\begin{array}{l}\text { Tensile modulus } \\
\qquad(\mathrm{GPa})\end{array}$ & $\begin{array}{l}\text { Tensile strength } \\
\text { (MPa) }\end{array}$ & Elongation (\%) & $\begin{array}{c}\text { Fracture } \\
\text { toughness } \\
\left(\mathrm{MPa} \cdot \mathrm{m}^{0.5}\right)\end{array}$ & $\begin{array}{l}\text { Strain energy } \\
\qquad\left(\mathrm{J} / \mathrm{m}^{2}\right)\end{array}$ & $\begin{array}{c}\text { Glass transition } \\
\text { temp. }\left({ }^{\circ} \mathrm{C}\right)\end{array}$ \\
\hline 0 (neat epoxy) & $2.82 \pm 0.08$ & $82.2 \pm 1.56$ & $8.53 \pm 0.16$ & $0.78 \pm 0.05$ & $235 \pm 28$ & 117 \\
\hline 1 wt\% I.30E (U) & $3.25 \pm 0.04$ & $84.7 \pm 1.56$ & $6.12 \pm 0.5$ & $0.79 \pm 0.03$ & $225 \pm 11$ & 115 \\
\hline 2 wt\% I.30E (U) & $3.23 \pm 0.04$ & $80.6 \pm 2.78$ & $5.51 \pm 0.97$ & $0.81 \pm 0.05$ & $245 \pm 12$ & 114 \\
\hline 3 wt\% I.30E (U) & $3.36 \pm 0.03$ & $76.7 \pm 3.51$ & $4.08 \pm 0.56$ & $0.77 \pm 0.01$ & $230 \pm 9$ & 112 \\
\hline 1 wt\% I.30E (M) & $2.84 \pm 0.03$ & $72.8 \pm 3.5$ & $4.8 \pm 0.75$ & $0.78 \pm 0.04$ & $240 \pm 26$ & 113 \\
\hline 2 wt\% I.30E (M) & $2.92 \pm 0.02$ & $69.8 \pm 0.42$ & $3.96 \pm 0.07$ & $0.83 \pm 0.04$ & $265 \pm 30$ & 113 \\
\hline 3 wt\% I.30E (M) & $2.97 \pm 0.01$ & $69.1 \pm 1.19$ & $3.78 \pm 0.17$ & $0.93 \pm 0.06$ & $320 \pm 32$ & 114 \\
\hline
\end{tabular}

${ }^{a} \mathrm{U}$ : ultrasonic mixing; M: mechanical mixing.

do not satisfy the temperature requirement for the DGEBA homopolymerization to be an operative mechanism [31].

From the XRD and TEM investigations some distinctions can be made between the morphologies of the nanocomposites made by different dispersion methods. On the microscale, ultrasonic mixing caused deaggregation of the large layered silicate clusters, and on the nanoscale, it promoted intragallery diffusion of the epoxy prepolymer and the curing agent allowing the development of long range ordered structures (i.e., intercalated clay). In contrast, mechanical mixing produced larger clay aggregates with predominantly phase-separated clay tactoids. The ultrasonic method caused breaking-up of the large clay aggregates into finely dispersed uniformly distributed submicron-size clay particles as shown in Figure 3(b) $[18,20]$. However, neither of the dispersion methods achieved homogenously dispersed isolated exfoliated platelets resembling a monolithic structure for the nanocomposites. Similar observations have been documented by other researchers based on micro- and nanoscale studies on epoxy layered silicate nanocomposites $[7,14]$.

3.2. Tensile Property of the Epoxy-Clay Nanocomposites. The average tensile property values of each nanocomposite set were determined from test done on at least four specimens. Tensile properties of the nanocomposites are presented in Table 2 along with the corresponding standard deviations for a $68 \%$ confidence interval. The tensile test results of the nanocomposites and the unfilled epoxy resin are presented in Figures 5 to 7 with corresponding clay loadings. The lines drawn in the graphs illustrate general trends in the data but are not intended to signify any mathematical correlation. Error bars represent one standard deviation of four tests done on each set of specimens. The tensile modulus and strength of the pristine epoxy were measured to be $2.8 \mathrm{GPa}$ and $82 \mathrm{Mpa}$, respectively. The tensile modulus of the nanocomposites prepared by ultrasonic blending increased substantially; that is, a maximum of $20 \%$ increase was observed in response to $3 \mathrm{wt} \% \mathrm{I} .30 \mathrm{E}$ nanoclay addition. Stiffness improved slightly in the nanocomposites processed by a mechanical agitator for the same clay loadings. The degree of exfoliation of the high aspect ratio rigid nanoplatelets and superior interfacial adhesion of the exfoliated/intercalated nanoclay with the epoxy polymer contributed to the substantial stiffness improvement

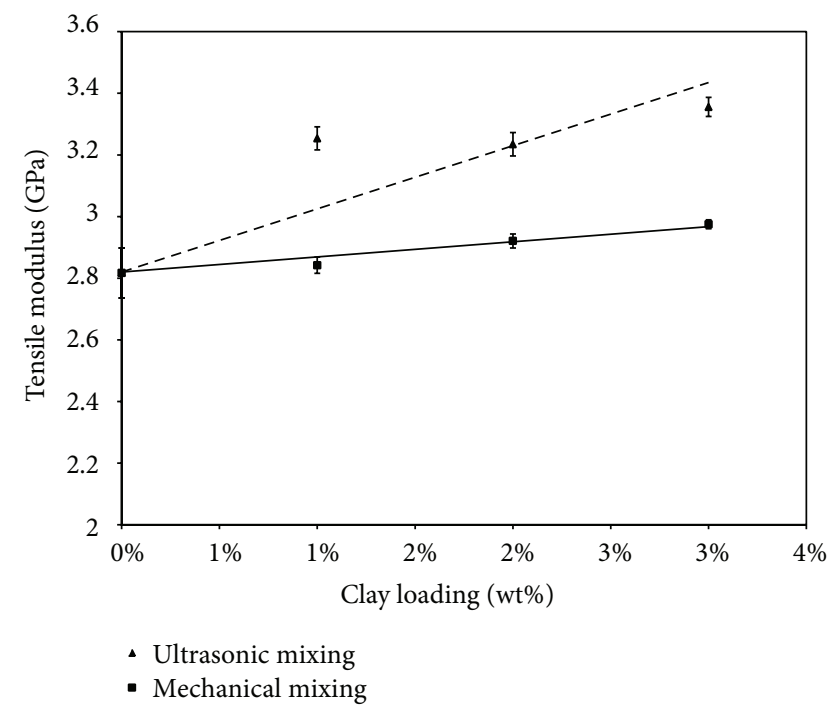

FIGURE 5: Influence of I.30E clay concentration on tensile modulus of nanocomposites.

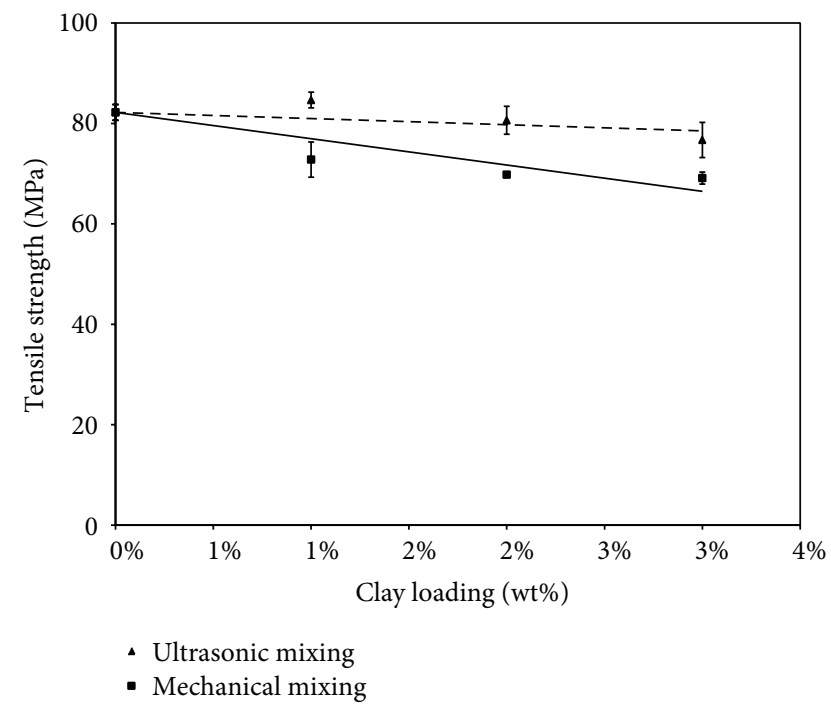

FIGURE 6: Tensile strength of nanocomposites as a function of I.30E clay content. 


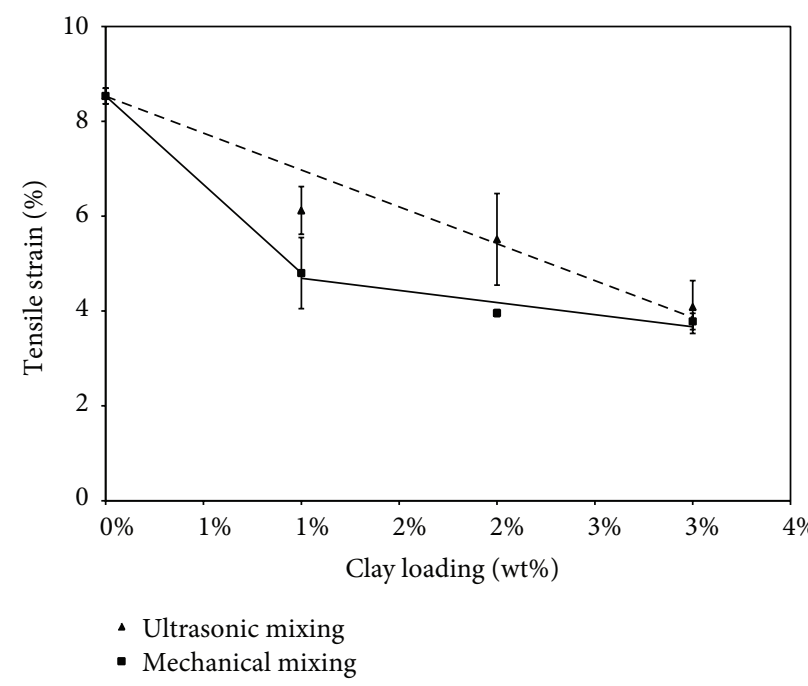

FIGURE 7: Relation between tensile elongation and I.30E clay loading of nanocomposites.

in the case of ultrasonically mixed nanocomposites [24]. It can be surmised that well-intercalated uniformly dispersed smaller submicron-size I.30E clay particles further influenced the stiffness. In contrast, for the mechanically mixed samples, the modulus increase was relatively small, probably in part due to the inefficient layer separation of the nanoclay. In addition, the phase-separated clay aggregates formed during the mechanical mixing behaved akin to conventional microparticles that require higher filler concentrations to achieve substantial stiffness enhancement.

Tensile strength values remained almost unchanged for samples formulated by ultrasonic mixing (see Figure 6). Nanocomposites that were made by the mechanical mixing method exhibited a considerable loss in tensile strength, which is in agreement with the results reported by other researchers [23]. It is assumed that clay aggregates present in the epoxy matrix acted as stress concentrators during the loading process causing the composite to fail at a reduced load level and ductility $[7,23]$. Strain values at break reduced significantly with the addition of clay nanoparticles in the epoxy matrix for all of the clay nanocomposites (see Figure 7). The reduction in tensile elongation is believed to stem from an embrittlement effect caused by the stiffer clay nanofillers in the epoxy network $[22,23]$.

\subsection{Fracture Property of the Epoxy-Clay Nanocomposites.} At least four specimens were tested for each epoxy-clay nanocomposite except that the $3 \mathrm{wt} \%$ I.30E, $1 \mathrm{wt} \%$ I.28E, and $1 \mathrm{wt} \%$ PGW in epoxy (ultrasonic mixing samples) data are based on only three tests. Figure 8 shows the fracture toughness in the form of critical stress intensity factor of the neat epoxy and its nanocomposites for respective nanoclay loadings. The fracture toughness and the strain energy release rate of the neat epoxy were measured as $0.78 \mathrm{MPa} \mathrm{m}^{0.5}$ and $235 \mathrm{~J} \mathrm{~m}^{-2}$, respectively. For the ultrasonically produced nanocomposites, the toughness values remained almost

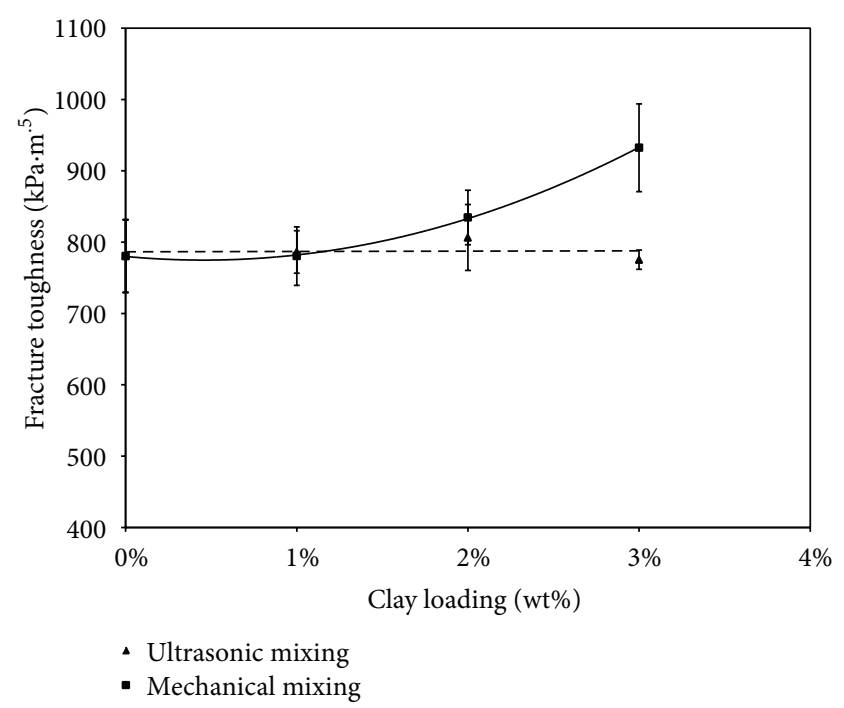

FIGURE 8: Influence of I.30E clay concentration on fracture toughness of nanocomposites.

identical to that of the pristine epoxy. However, the fracture toughness increased substantially for the mechanical dispersion method. The mechanical dispersion method seems to be more effective than the ultrasonic mixing method in toughening epoxy. Similar behavior was also observed for the critical stain energy release rate; for example, by mechanically mixing $3 \mathrm{wt} \%$ of I.30E clay with epoxy, an increase of about $35 \%$ was observed relative to the unmodified epoxy (see Table 2). Figure 9 shows fracture energies of the nanocomposites each containing $1 \mathrm{wt} \%$ of a specific type of the organosilicates. It is demonstrated that the quaternary alkylammonium ion exchanged montmorillonite affords a substantial improvement in epoxy toughness compared to the primary alkylammonium ion. This finding is in agreement with observations previously made by Zilg et al. [8], who found that conventional composites as well as quaternary ammonium ion exchanged fluoromica-filled epoxy showed higher toughness than nanocomposites based on protonated primary amines.

In the present investigation, it is concluded that the epoxy-clay nanocomposites with phase-separated and flocculated morphology provided better crack resistance than the nanocomposite with exfoliated and intercalated structures. It has been documented in the literature that in nanoclay modified epoxy, crack deflection and bifurcation $[19,26,28]$, crack pinning $[19,26]$, and matrix deformation $[19,28]$ are the most commonly observed crack resistance mechanisms. Matrix deformation and crack pinning are the dominant energy absorption mechanisms since the crack deflection phenomenon enhances toughness only to a limited extent [32]. Crack resistance phenomena are further explored with regard to the micromechanisms of the fracture process in the following section.

3.4. Fractographic Study of the Epoxy-Clay Nanocomposites. Figure 10 shows a smooth and featureless fracture surface of 


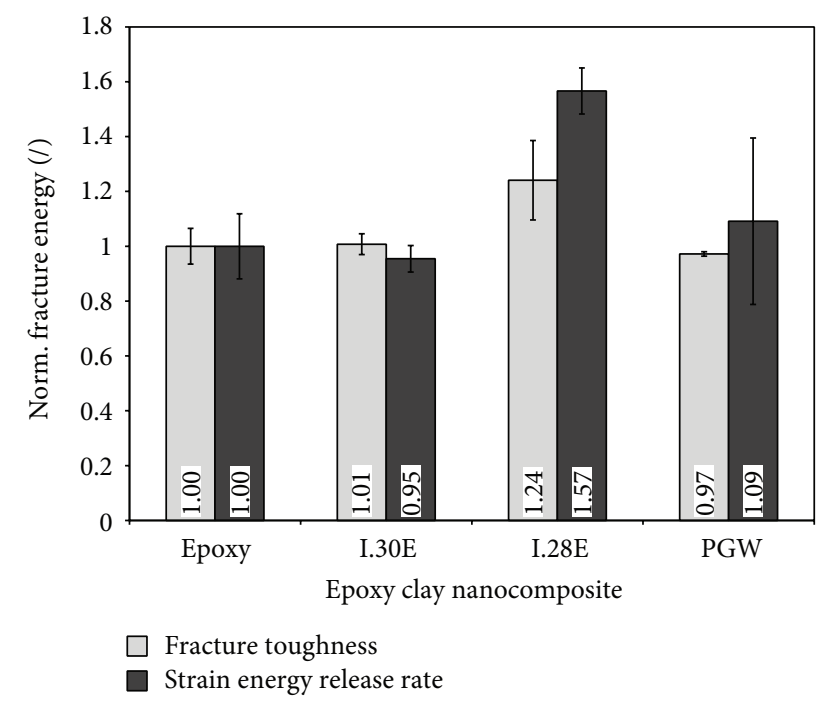

FIGURE 9: Fracture energy of the different nanoclay reinforced nanocomposites prepared by ultrasonic mixing.

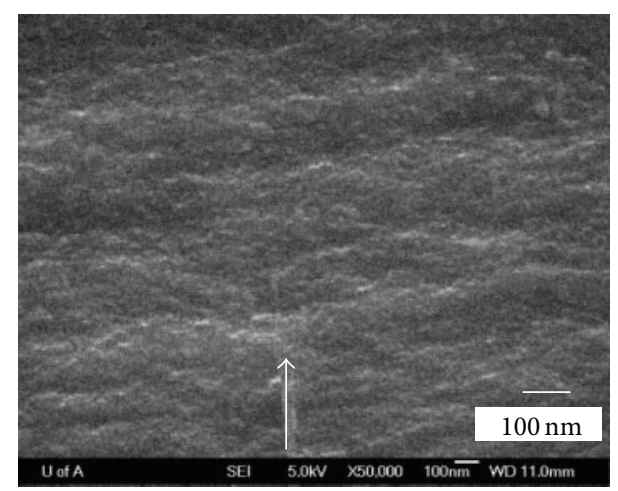

FIGURE 10: SEM micrograph of a neat epoxy fracture surface.

the unfilled epoxy representing insignificant matrix deformation that is usually observed in a homogenous brittle material. Note that arrows in the fractographic images illustrate the crack propagation direction. In general, the fracture surface of the modified epoxy was coarse and rough, the result of crack propagation through intricate and perturbed paths. Figure 11 shows fracture surfaces of the nanocomposites made by blending I.30E clay with epoxy using the ultrasonic probe. The higher magnification images in Figures 11(a)11(c) exhibit epoxy network penetration in between the silicate layers, which correlates well with the intercalated morphology observed by TEM microscopy. Clear evidence of the distorted and perturbed crack path can be seen in Figures 11(d)-11(f). These tortuous paths were caused by a crack deflection mechanism when the path of a propagating crack was impeded by the uniformly distributed nanoparticles (i.e., both the intercalated parallel platelets and partially exfoliated platelets). As this nanocomposite is mostly composed of intercalated clay structures, one would expect to see an increase in fracture toughness, but the smaller submicronsize intercalated clay tactoids behaved akin to exfoliated platelets. This notion was corroborated by the strong increase in modulus values [33]. The above observations lead to the inference that in this particular epoxy system, the occurrence of crack deflection mechanism only provided insignificant energy dissipation [32]. Void formation and cavitation were not observed, so there was an excellent interfacial interaction between the epoxy matrix and clay in an exfoliated and intercalated structure as had been predicted.

Figure 12 shows SEM images of the fracture surface of mechanically mixed nanocomposites showing agglomerated clay of various sizes. The appearance of the textured surface, steps, and clusters are indicative of a significant consumption of fracture energy. Figure 12(a) depicts a high magnification micrograph of phase-separated clay structure. Fractographic evidence suggests that at a low clay concentration, agglomerated micron-size I.30E clay resulted in crack deflection and crack pinning mechanisms being operative. This behavior closely resembles that of conventional microparticles. Characteristic pinning tails can be seen behind the particles. Such step structures form when crack fronts from two different fracture planes meet each other after being blocked by inclusions. It is known that in a brittle matrix when a crack front is obstructed and pinned down by a rigid wellbonded particle, the crack front becomes bowed out between the particles resulting in secondary cracks. Consequently, more energy would be necessary to propagate this new nonlinear crack front, which also depends on the particle size and the interparticle spacing. Previously, Moloney et al. [34] observed that the crack-pinning mechanism was responsible for increasing fracture toughness in silica and alumina modified epoxy. In another study, Kinloch et al. [35] discussed crack pinning mechanism in glass particle-filled epoxy citing the fractographic evidence of crack bowing and experimental fracture energy values. In the present study, it was also observed that the size of clay aggregates increases with increasing clay concentration, while at the same time interparticle distance decreases and roughness increases. The fracture surface shown in Figure 12(d) for a higher clay content of $3 \mathrm{wt} \%$ provides evidence for matrix deformation and particle debonding - this further distinguishes the composites prepared by the mechanical dispersion. At higher concentration, the clay agglomerates may act as stress concentrators during the fracture process and instigate localized matrix shear yielding around the clay inclusions or cause interfacial failure at the epoxy-clay interface.

The fracture surface topology of the I.28E clay modified epoxy shown in Figure 13(a) is extremely textured and coarse. This convoluted surface morphology confirms the occurrence of the crack deflection and crack pinning operations associated with localized matrix deformation. It appears that I.28E nanoclay assembled into uniformly distributed closely spaced microstructures in the epoxy matrix. It is conjectured that these intercalated clay assemblies were in fact very efficient in inhibiting the crack propagation by pinning mechanism. In the corresponding fracture surface, the pinning tails were overshadowed by interacting secondary crack planes. As expected, the fracture surface of epoxy with 


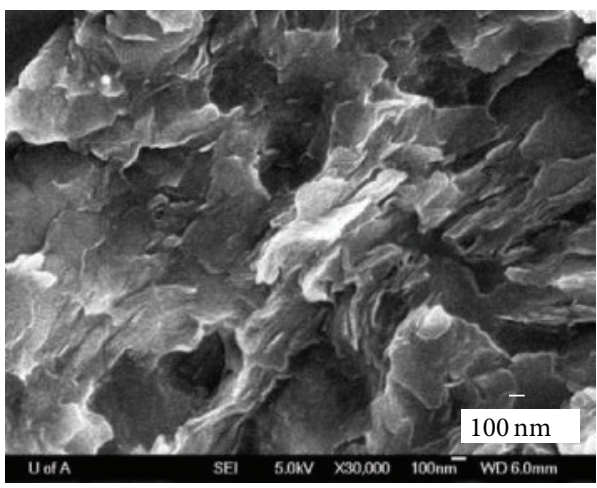

(a)

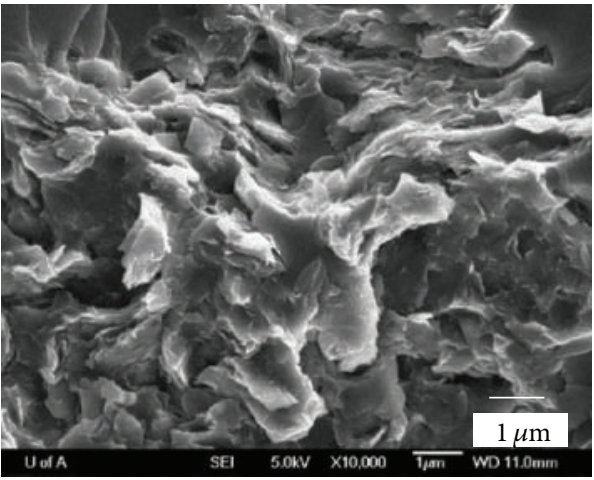

(b)

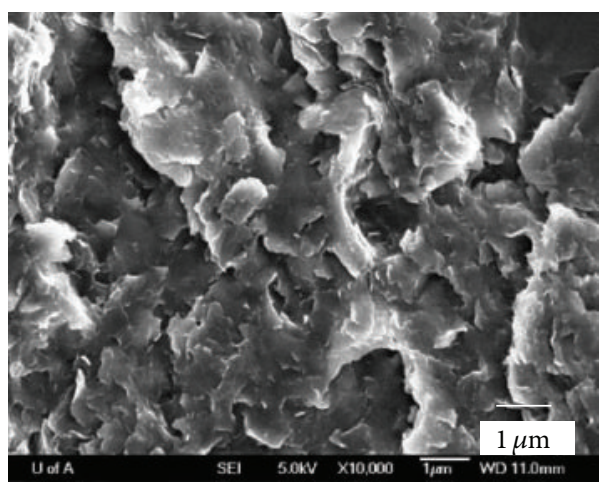

(c)

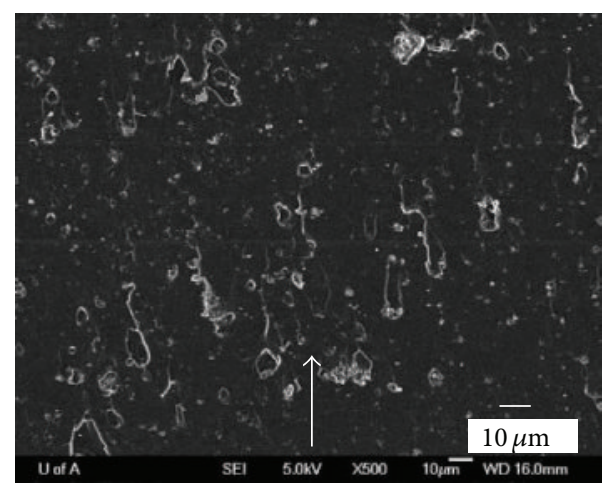

(d)

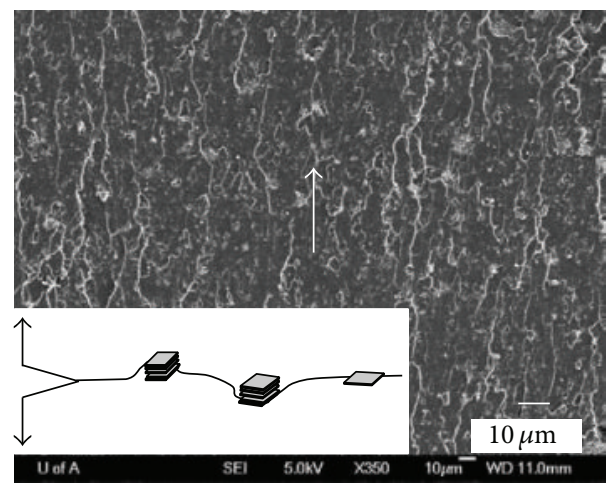

(e)

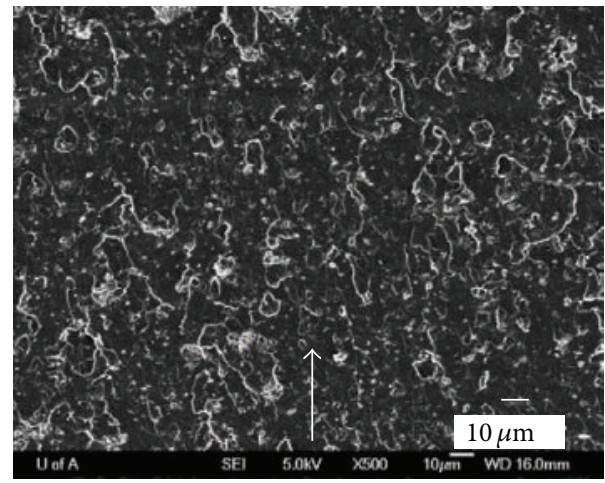

(f)

FIGURE 11: Fracture surface micrographs (SEM) of nanocomposites made by ultrasonic dispersion of (a) $1 \mathrm{wt} \%$, (b) $2 \mathrm{wt} \%$, and (c) $3 \mathrm{wt} \%$ I.30E clay (high magnification pictures) and (d) $1 \mathrm{wt} \%$, (e) $2 \mathrm{wt} \%$, and (f) $3 \mathrm{wt} \%$ I.30E clay (low magnification pictures) in epoxy. The inserted schematic shows associated crack deflection mechanism.

PGW clay is relatively featureless and devoid of substantial matrix damage reminiscent of the fracture surface of neat epoxy.

\section{Conclusions}

The present study explores how variations in the nanoclay dispersion method can significantly affect the morphology and, hence, the mechanical properties of epoxy nanocomposites. In the case of primary alkylammonium exchanged clay (I.30E), the microscopic study and XRD traces of the nanocomposites revealed the creation of partly exfoliated and laminated silicate layers by ultrasonic dispersion and a mixture of intercalated and phase-separated clay agglomerates by mechanical blending. The quaternary alkylammonium treated (I.28E) and unmodified clay (PGW) assembled into intercalated clay tactoids and phase-separated microaggregates in the epoxy matrix, respectively.

The final properties of the nanocomposites were found to be very much dependent on the macrostructure of 


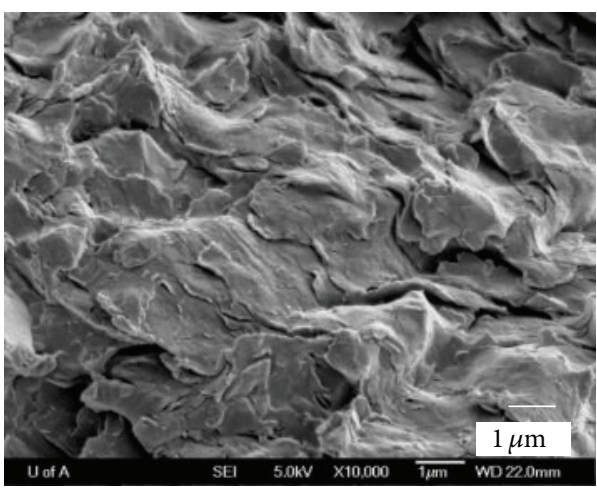

(a)

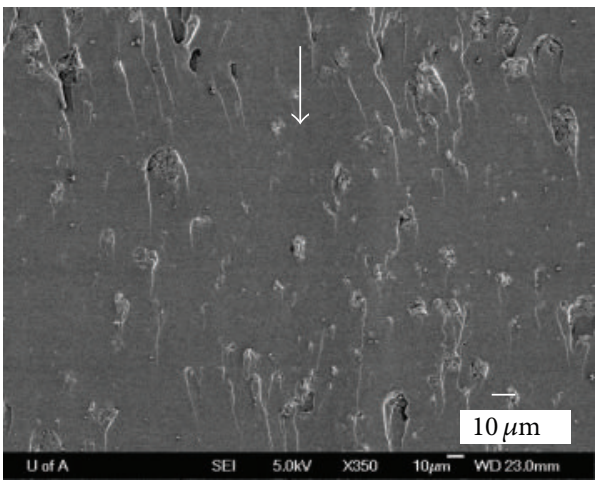

(c)

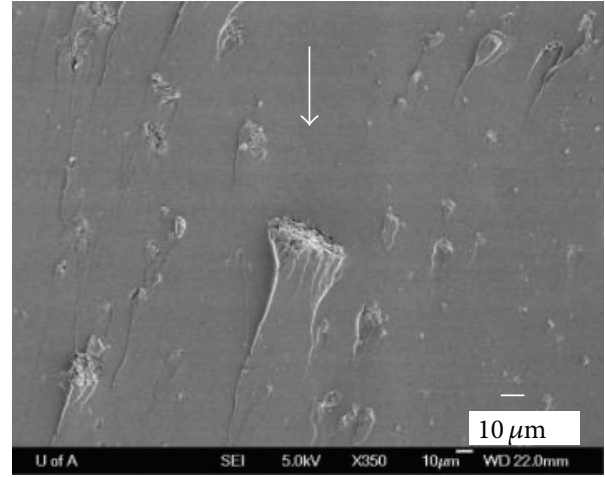

(b)

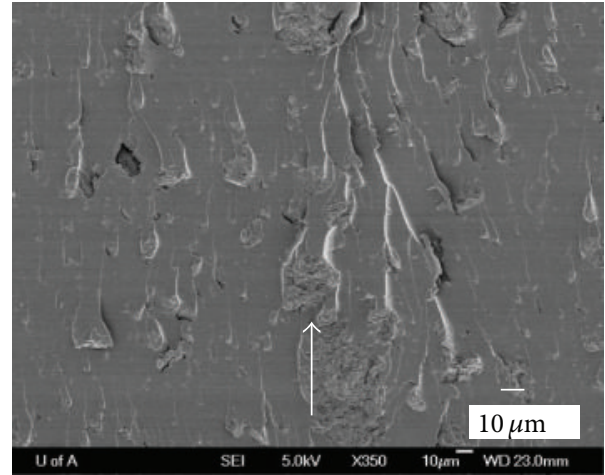

(d)

FIGURE 12: Fracture surface micrographs (SEM) of nanocomposites made by mechanical dispersion of (a) 1 wt\% (high magnification), (b) $1 \mathrm{wt} \%$, (c) $2 \mathrm{wt} \%$, and (d) $3 \mathrm{wt} \%$ I.30E clay in epoxy.

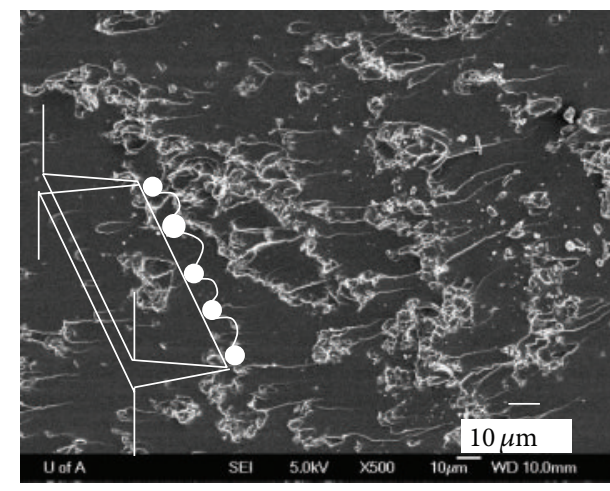

(a)

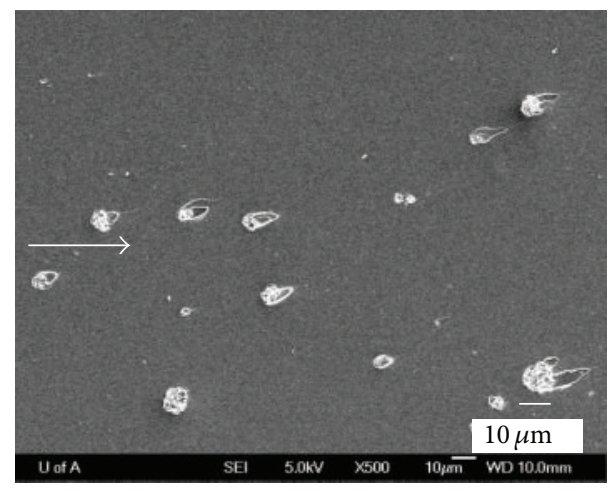

(b)

FIGURE 13: Fracture surface micrographs (SEM) of nanocomposites comprised of (a) $1 \mathrm{wt} \%$ I.28E (the schematic shows crack pinning mechanism) and (b) $1 \mathrm{wt} \%$ PGW clay in epoxy.

the nanoclay inclusion. Although full exfoliation was not achieved in any of the nanocomposite systems, considerable stiffness increase was observed for ultrasonically dispersed I.30E clay. An enhancement in modulus was attributed to a combined reinforcing effect of partially delaminated clay platelets and intercalated submicron clay tactoids, whereas toughness was found to be independent of silicate layer separation. In contrast, the phase-separated and agglomerated
I.30E clay from mechanical dispersion and the intercalated I.28E clay provided substantial fracture resistance. It is speculated that microreinforcements through crack deflection, pinning, and matrix deformation mechanisms are the key to providing high crack propagation resistance. This study highlights the fact that the types of organic modifier and the processing method have significant influence on the ultimate properties of the nanocomposites. 


\section{Conflict of Interests}

The authors declare that there is no conflict of interests regarding the publication of this paper.

\section{Acknowledgments}

The authors want to thank Bernie Faulkner for helping with test setup and lab assistance. They also thank Randy Mandryk, Diane Caired, and George Braybrooke for providing analytical and experimental resources.

\section{References}

[1] L. A. Utracki, Clay-Containg Polymeric Nanocomposites, Rapra Technology, Shawbury, UK, 2004.

[2] S. C. Roh, H. J. Kwan, and C. K. Kim, "Nanocomposites of novolac type phenolic resins and organoclays: the effects of the resin molecular weight and the amine salt structure on the morphology and the mechanical properties of the composites," Macromolecular Research, vol. 20, no. 5, pp. 496-502, 2012.

[3] F. Hussain, M. Hojjati, M. Okamoto, and R. E. Gorga, "Review article: polymer-matrix nanocomposites, processing, manufacturing, and application: an overview," Journal of Composite Materials, vol. 40, no. 17, pp. 1511-1575, 2006.

[4] E. P. Giannelis, "Polymer layered silicate nanocomposites," Advanced Materials, vol. 8, no. 1, pp. 29-35, 1996.

[5] T. Lan and T. J. Pinnavaia, "Clay-reinforced epoxy nanocomposites," Chemistry of Materials, vol. 6, no. 12, pp. 2216-2219, 1994.

[6] P. B. Messersmith and E. P. Giannelis, "Synthesis and characterization of layered silicate-epoxy nanocomposites," Chemistry of Materials, vol. 6, no. 10, pp. 1719-1725, 1994.

[7] X. Kornmann, R. Thomann, R. Mülhaupt, J. Finter, and L. Berglund, "Synthesis of amine-cured, epoxy-layered silicate nanocomposites: the influence of the silicate surface modification on the properties," Journal of Applied Polymer Science, vol. 86, no. 10, pp. 2643-2652, 2002.

[8] C. Zilg, R. Mülhaupt, and J. Finter, "Morphology and toughness/stiffness balance of nanocomposites based upon anhydride-cured epoxy resins and layered silicates," Macromolecular Chemistry and Physics, vol. 200, no. 3, pp. 661-670, 1999.

[9] X. Kornmann, L. A. Berglund, R. Thomann, R. Mulhaupt, and J. Finter, "High performance epoxy-layered silicate nanocomposites," Polymer Engineering and Science, vol. 42, no. 9, pp. 18151826, 2002.

[10] J. M. Brown, D. Curliss, and R. A. Vaia, "Thermoset-layered silicate nanocomposites. Quaternary ammonium montmorillonite with primary diamine cured epoxies," Chemistry of Materials, vol. 12, no. 11, pp. 3376-3384, 2000.

[11] M. Alexandre and P. Dubois, "Polymer-layered silicate nanocomposites: preparation, properties and uses of a new class of materials," Materials Science and Engineering R: Reports, vol. 28, no. 1, pp. 1-63, 2000.

[12] T. Lan, P. D. Kaviratna, and T. J. Pinnavaia, "Mechanism of clay tactoid exfoliation in epoxy-clay nanocomposites," Chemistry of Materials, vol. 7, no. 11, pp. 2144-2150, 1995.

[13] C. Chen and D. Curliss, "Preparation, characterization, and nanostructural evolution of epoxy nanocomposites," Journal of Applied Polymer Science, vol. 90, no. 8, pp. 2276-2287, 2003.
[14] X. Kornmann, H. Lindberg, and L. A. Berglund, "Synthesis of epoxy-clay nanocomposites: influence of the nature of the clay on structure," Polymer, vol. 42, no. 4, pp. 1303-1310, 2001.

[15] J. H. Park and S. C. Jana, "Mechanism of exfoliation of nanoclay particles in epoxy-clay nanocomposites," Macromolecules, vol. 36, no. 8, pp. 2758-2768, 2003.

[16] O. Becker, Y. Cheng, R. J. Varley, and G. P. Simon, "Layered silicate nanocomposites based on various high-functionality epoxy resins: the influence of cure temperature on morphology, mechanical properties, and free volume," Macromolecules, vol. 36, no. 5, pp. 1616-1625, 2003.

[17] O. Becker, R. Varley, and G. Simon, "Morphology, thermal relaxations and mechanical properties of layered silicate nanocomposites based upon high-functionality epoxy resins," Polymer, vol. 43, no. 16, pp. 4365-4373, 2002.

[18] M. Hernandez, B. Sixou, J. Duchet, and H. Sautereau, "The effect of dispersion state on PMMA-epoxy-clay ternary blends: in situ study and final morphologies," Polymer, vol. 48, no. 14, pp. 4075-4086, 2007.

[19] W. Liu, S. V. Hoa, and M. Pugh, "Organoclay-modified high performance epoxy nanocomposites," Composites Science and Technology, vol. 65, no. 2, pp. 307-316, 2005.

[20] H. Miyagawa and L. T. Drzal, "The effect of chemical modification on the fracture toughness of montmorillonite clay/epoxy nanocomposites," Journal of Adhesion Science and Technology, vol. 18, no. 13, pp. 1571-1588, 2004.

[21] T. J. Pinnavaia, T. Lan, Z. Wang, H. Shi, and P. D. Kaviratna, "Clay-reinforced epoxy nanocomposites: synthesis, properties, and mechanism of formation," ACS Symposium Series, vol. 622, pp. 250-261, 1996.

[22] P. I. Xidas and K. S. Triantafyllidis, "Effect of the type of alkylammonium ion clay modifier on the structure and ther$\mathrm{mal} /$ mechanical properties of glassy and rubbery epoxy-clay nanocomposites," European Polymer Journal, vol. 46, no. 3, pp. 404-417, 2010.

[23] A. S. Zerda and A. J. Lesser, "Intercalated clay nanocomposites: morphology, mechanics, and fracture behavior," Journal of Polymer Science B: Polymer Physics, vol. 39, no. 11, pp. 1137-1146, 2001.

[24] A. Yasmin, J. L. Abot, and I. M. Daniel, "Processing of clay/epoxy nanocomposites by shear mixing," Scripta Materialia, vol. 49, no. 1, pp. 81-86, 2003.

[25] A. J. Kinloch and A. C. Taylor, "Mechanical and fracture properties of epoxy/inorganic micro- and nano-composites," Journal of Materials Science Letters, vol. 22, no. 20, pp. 1439-1441, 2003.

[26] N. A. Siddiqui, R. S. C. Woo, J.-K. Kim, C. C. K. Leung, and A. Munir, "Mode I interlaminar fracture behaviour and mechanical properties of CFRPs with nanoclay-filled epoxy matrix," Composites A: Applied Science and Manufacturing, vol. 38, pp. 449-460, 2007.

[27] K. Wang, L. Chen, J. Wu, M. L. Toh, C. He, and A. F. Yee, "Epoxy nanocomposites with highly exfoliated clay: mechanical properties and fracture mechanisms," Macromolecules, vol. 38, no. 3, pp. 788-800, 2005.

[28] T. Liu, W. C. Tjiu, Y. Tong, C. He, S. S. Goh, and T. Chung, "Morphology and fracture behavior of intercalated epoxy/clay nanocomposites," Journal of Applied Polymer Science, vol. 94, no. 3, pp. 1236-1244, 2004.

[29] J. M. Hutchinson, F. Shiravand, and Y. Calventus, "Intra- and extra-gallery reactions in tri-functional epoxy polymer layered 
silicate nanocomposites," Journal of Applied Polymer Science, vol. 128, no. 5, pp. 2961-2970, 2013.

[30] ASTM International, "Standard test methods for plane-strain fracture toughness and strain energy release rate of plastic materials," Tech. Rep. ASTM D5045-99, ASTM International, West Conshohocken, Pa, USA, 1999.

[31] M. S. Wang and T. J. Pinnavaia, "Clay-polymer nanocomposites formed from acidic derivatives of montmorillonite and an epoxy resin," Chemistry of Materials, vol. 6, no. 4, pp. 468-474, 1994.

[32] A. C. Garg and Y. Mai, "Failure mechanisms in toughened epoxy resins-a review," Composites Science and Technology, vol. 31, no. 3, pp. 179-223, 1988.

[33] M. Bashar, U. Sundararaj, and P. Mertiny, "Microstructure and mechanical properties of epoxy hybrid nanocomposites modified with acrylic tri-block-copolymer and layered-silicate nanoclay," Composites A: Applied Science and Manufacturing, vol. 43, no. 6, pp. 945-954, 2012.

[34] A. C. Moloney, H. H. Kausch, and H. R. Stieger, "The fracture of particulate-filled epoxide resins-part 1," Journal of Materials Science, vol. 18, no. 1, pp. 208-216, 1983.

[35] A. J. Kinloch, D. L. Maxwell, and R. J. Young, "The fracture of hybrid-particulate composites," Journal of Materials Science, vol. 20, no. 11, pp. 4169-4184, 1985. 

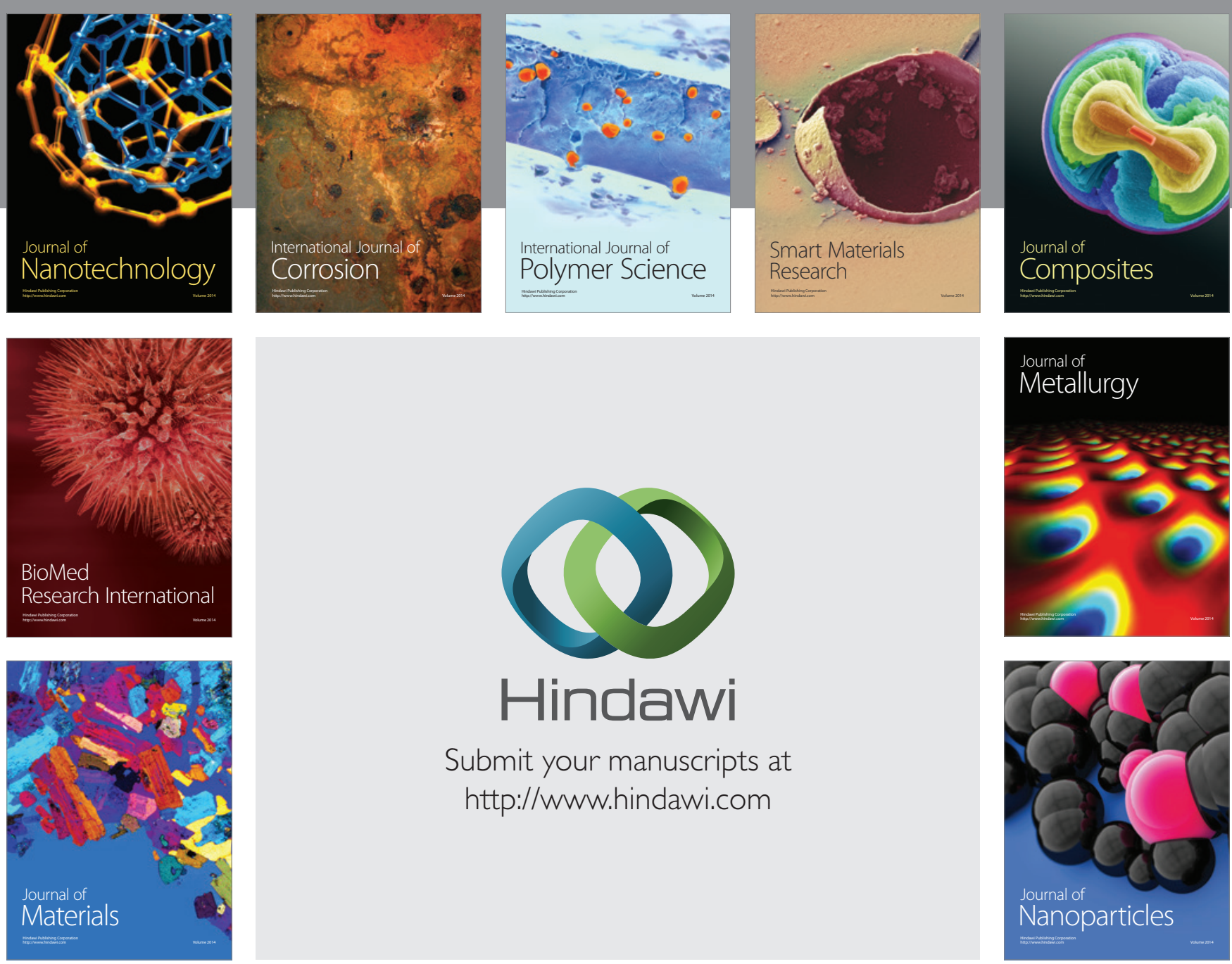

Submit your manuscripts at http://www.hindawi.com
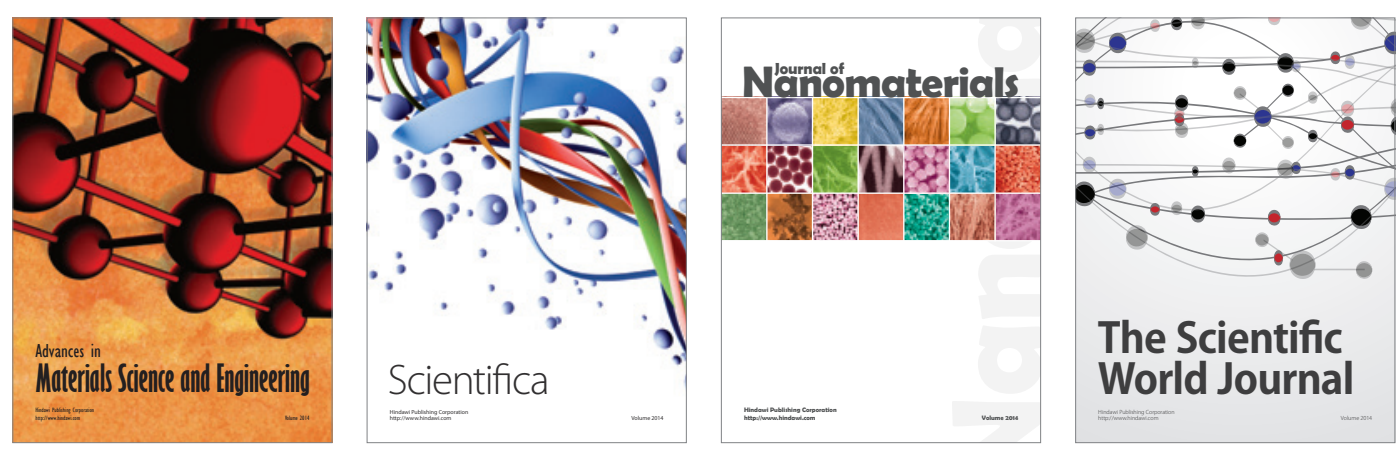

\section{The Scientific World Journal}
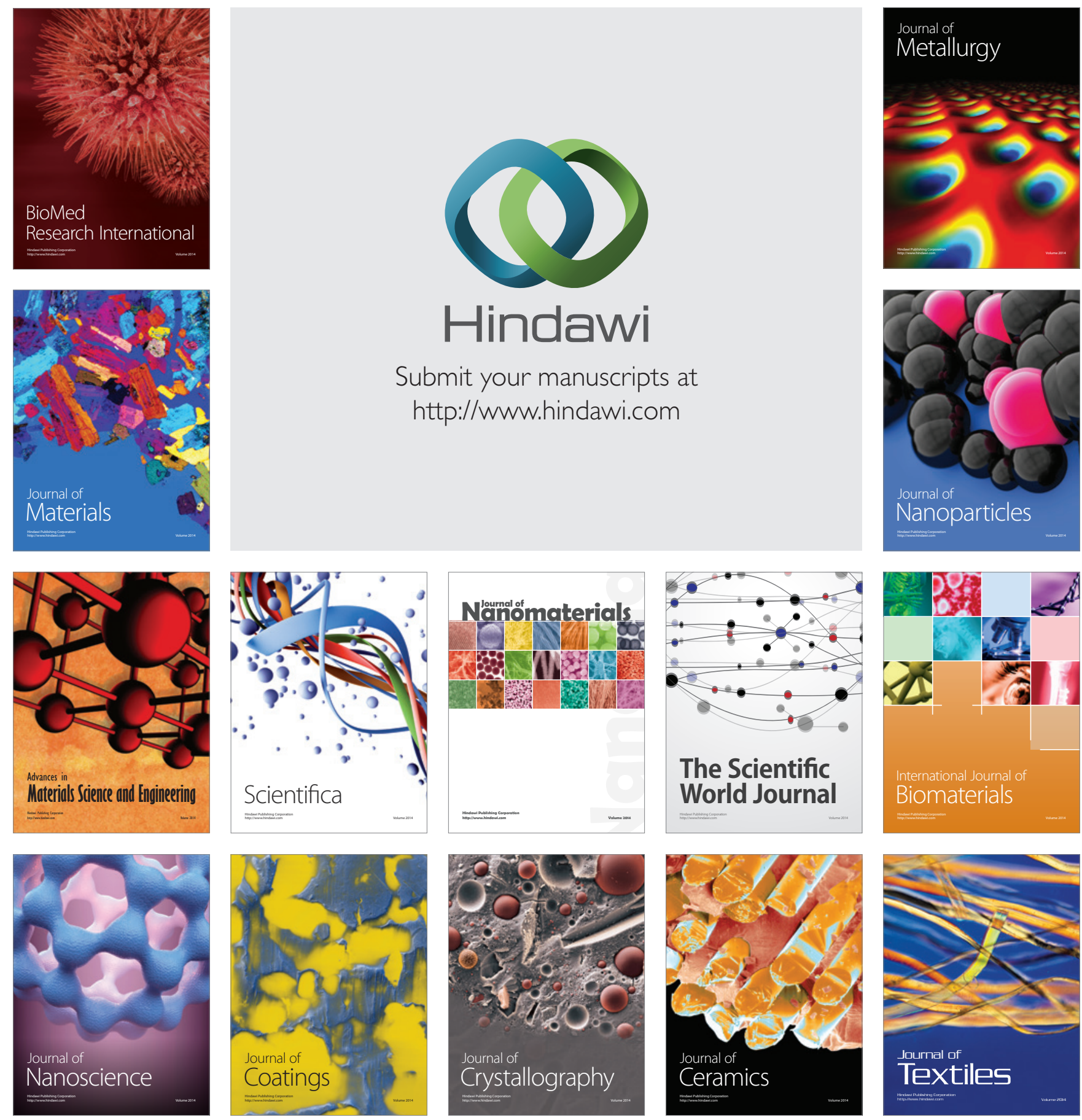